Article

\title{
Electrochemical Corrosion Behavior of Near-Nano and Nanostructured WC-Co Cemented Carbides
}

\author{
Željko Alar, Vesna Alar and Tamara Aleksandrov Fabijanić * \\ Faculty of Mechanical Engineering and Naval Architecture, University of Zagreb, Ivana Lučića 5, 10000 Zagreb, \\ Croatia; zalar@fsb.hr (Ž.A.); vesna.alar@fsb.hr (V.A.) \\ * Correspondence: tamara.aleksandrov@fsb.hr; Tel.: +385-1-6118-389
}

Academic Editor: Kevin Plucknett

Received: 1 December 2016; Accepted: 17 February 2017; Published: 23 February 2017

\begin{abstract}
In this paper, the electrochemical corrosion resistance of near-nano and nanostructured WC-Co cemented carbides was investigated. WC powders with an average grain size $d_{\mathrm{BET}}$ in the range from $95 \mathrm{~nm}$ to $150 \mathrm{~nm}$ and with an addition of vanadium carbide (VC) and chromium carbide $\mathrm{Cr}_{3} \mathrm{C}_{2}$ as grain growth inhibitors were used as starting powders. The mixtures with $6 \mathrm{wt}$. \% and 9 wt. \% Co were consolidated by two different processes; sintering in hydrogen atmosphere and the sinter-HIP process. WC-Co samples were researched by direct current and alternating current techniques in the solution of $3.5 \% \mathrm{NaCl}$ at room temperature. Corrosion parameters such as corrosion potential $\left(E_{\text {corr }}\right)$, corrosion current density $\left(j_{\text {corr }}\right)$ and polarization resistance $\left(R_{\mathrm{p}}\right)$ were determined by electrochemical techniques. From the conducted research, it was found that the consolidation processes and microstructural characteristics-grain growth inhibitors, grain size of the starting WC powders and $\eta$-phase-influenced the electrochemical corrosion resistance. $\eta$-phase enhanced the formation of a passive layer on the samples' surfaces, thereby reducing the tendency of the sample dissolution and increasing the stability of oxides forming therewith a passive layer on the sample surface.
\end{abstract}

Keywords: near-nano and nanostructured cemented carbides; corrosion potential; corrosion current density; polarization resistance; grain growth inhibitors; $\eta$-phase; WC grain size

\section{Introduction}

Corrosion resistance and electrochemical properties are not a prime requirement of cemented carbides, nevertheless, these properties are very important in industrial use since the application area of cemented carbides is rapidly growing due to their superior mechanical properties, high hardness and high toughness, and good wear resistance [1-4]. Cemented carbides are used in the chemical and petroleum industry for applications such as flow control components, oil and gas inserts such as drill bits, drilling rigs, brag bit profiles, chisel buttons and metal forming tools where they are exposed to an aggressive environment which requires erosion and corrosion resistance [3,5]. Cemented carbides are susceptible to oxidation behavior, electrochemical corrosion and wet corrosion which can cause wear problems $[3,4]$. The corrosion mechanism occurring in cemented carbides depends on many influential factors which can be classified into two basic groups; one referring to the environment and another one to microstructural characteristics.

Many authors have shown that the rate of corrosion depends on the concentration and temperature of corrosive fluids, exposure time, and most of all, on the $\mathrm{pH}$ of the fluid [2]. Conventional WC-Co cemented carbides are characterized by poor corrosion resistance in acid or neutral aqueous solutions for $\mathrm{pH} \leq 7$ due to the susceptibility of Co to wet corrosion [3]. In neutral and acidic medium, the selective dissolution of the Co matrix occurs while WC particles are not affected by the corrosion attack; while at alkaline $\mathrm{pH}$ values, the passivation of the Co matrix occurs and WC is dissolved [3-6]. 
A study from a group of authors demonstrated that the presence of aggressive anions, $\mathrm{Cl}^{-}$and $\mathrm{SO}_{4}{ }^{2-}$ stimulates the speed of anode dissolution [4]. Pitting corrosion observed in the presence of $\mathrm{Cl}^{-}$anions and $\mathrm{SO}_{4}{ }^{2-}$ anions causes indirect impact on the acceleration of the cathodic reaction and significantly affects the anodic reaction $[4,6]$. Accordingly, it is very important to take into account the operating medium parameters such as $\mathrm{pH}$ value, temperature and conductivity. It is evident that WC-Co hardmetals are characterized by poor resistance to acidic media, while WC-Ni hardmetals are stable in acidic solutions to $\mathrm{pH}=3$.

Besides environmental influences, the corrosion behavior of WC-Co cemented carbides is influenced by microstructural characteristics, such as the WC grain size, the amount of the binder phase and binder composition [2,7]. The conclusions found in the literature are contradictory. Human reported that the size of the WC grains does not show any effect on the corrosion behavior of the WC-10Co composite [4]. The latest research by Zhang showed that the corrosion resistance deteriorates with the increase of the WC grain sizes in neutral and alkaline medium while the corrosion resistance in acid medium increases with the increase of WC grain sizes [8]. The latest research of Tarrago points out that the medium grain-sized hardmetals exhibit higher damage tolerance to corrosion and better strength retention than the ultra-fine hardmetals [9]. The chemical nature of the binder significantly influences the corrosion behavior of cemented carbides. Until now, it is well known that using Ni instead of Co as binder can improve corrosion resistance. Refractory metal carbides which are added as grain grow inhibitors (GGIs) to ultrafine and especially nano-sized powders also influence the corrosion resistance (they have been found to increase the resistance to corrosion) $[10,11]$. Their influence is still a relatively under-researched area. According to Sutthiruangwong and Mori, the small addition of $0.5 \%$ $\mathrm{Cr}_{3} \mathrm{C}_{2}$ does not improve the corrosion resistance of WC-Co-cemented carbides while higher amounts of tungsten and/or chromium dissolved in the binder improve corrosion resistance [10]. Corrosion potential with an addition of $\mathrm{Cr}$ tends to more positive values, while adding $\mathrm{Cr}_{3} \mathrm{C}_{2}$ significantly reduces the current density. Mori [12] found that small additions, less than $0.5 \% \mathrm{TiC}$ and $\mathrm{TaC}$, have no influence on the corrosion resistance while adding between $4 \%$ and $8 \%$ is effective, but the mechanism is not yet fully explored.

Electrochemical corrosion resistance of nanostructured cemented carbides is an under-researched area. It is difficult to define an appropriate mechanism of corrosion and the influence of GGIs and WC powder size on the corrosion behavior of nanostructured cemented carbides. The presented research was performed in order to investigate the influence of the consolidation process and microstructural characteristics on the electrochemical corrosion resistance of near-nano and nanostructured cemented carbides.

\section{Materials and Methods}

Newly developed tungsten carbide WC near-nano and nano-powders WC DN 2-5 and WC DN 4-0 produced by HC Stark (Goslar, Germany) were used as starting materials. The powders have an average grain size $d_{\mathrm{BET}}$ in the range from $95 \mathrm{~nm}$ to $150 \mathrm{~nm}$ and a specific surface area (BET) in the range from $2.5 \mathrm{~m}^{2} / \mathrm{g}$ to $4.0 \mathrm{~m}^{2} / \mathrm{g}[13,14]$. Grain growth inhibitors GGIs were added to the starting WC powders. Four different mixtures were prepared as presented in Table 1.

Table 1. Characteristics of mixtures and samples.

\begin{tabular}{|c|c|c|c|c|c|c|}
\hline Mixture & Sample & WC Powder & Grain Size $d_{\mathrm{BET}}, \mathrm{nm}$ & GGI, wt $\%$ & Co, wt \% & Sintering Atmosphere \\
\hline \multirow{2}{*}{ WC9Co/1 } & WC-9Co/1V & WC DN & \multirow{2}{*}{150} & $0.26 \% \mathrm{VC}$ & 9 & Hydrogen \\
\hline & WC-9Co/1S & $2-5 / 1$ & & $0.45 \% \mathrm{Cr}_{3} \mathrm{C}_{2}$ & 9 & Sinter-HIP \\
\hline \multirow{2}{*}{ WC9Co/2 } & WC-9Co/2V & WC DN & \multirow{2}{*}{150} & \multirow{2}{*}{$0.27 \% \mathrm{VC}$} & 9 & Hydrogen \\
\hline & WC- 9 Co $/ 2 S$ & $2-5 / 2$ & & & 9 & Sinter-HIP \\
\hline \multirow[b]{2}{*}{ WC6Co/1 } & WC-6Co/1V & WC DN & \multirow[b]{2}{*}{150} & $0.26 \% \mathrm{VC}$ & 6 & Hydrogen \\
\hline & WC-6Co/1S & $2-5 / 1$ & & $0.45 \% \mathrm{Cr}_{3} \mathrm{C}_{2}$ & 6 & Sinter-HIP \\
\hline \multirow{2}{*}{ WC6Co/4 } & $\mathrm{WC}-6 \mathrm{Co} / 4 \mathrm{~V}$ & \multirow{2}{*}{ WC DN 4-0 } & \multirow{2}{*}{95} & $0.41 \% \mathrm{VC}$, & 6 & Hydrogen \\
\hline & WC-6Co/4S & & & $0.80 \% \mathrm{Cr}_{3} \mathrm{C}_{2}$ & 6 & Sinter-HIP \\
\hline
\end{tabular}


As can be seen from Table 1 above, the WC powders were mixed with 6 wt \% and 9 wt \% Co. The samples were sintered by two different processes; conventional liquid phase sintering in hydrogen and sinter-HIP in one cycle. Overall, eight samples were selected for examination. Samples were prepared for the porosity measurement and microstructure analysis. Etching for 2-3 s in a Murakami reagent was performed for the purpose of checking $\eta$-phase. The analysis was performed using an optical microscope (Olympus, Shinjuku, Tokyo, Japan) and a field emission scanning electron microscope (FESEM) (Tescan, Brno, Czech Republic). For the measurement of WC grain size, $d_{\text {WC }}$ was carried out by a conventional linear intercept method according to EN ISO 4499-2:2011. The surface of samples was polished and ultrasonically cleaned for the purpose of electrochemical measurement.

\section{Electrochemical Measurement}

The polished sample surface with the exposed area of $1 \mathrm{~cm}^{2}$ was immersed into the cell with electrolyte solution. A saturated calomel electrode SCE (SCHOTT Instruments GmbH, Mainz, Germany) was used as a reference electrode while graphite wires were used as a counter electrode. A Haber-Luggin capillary was inserted close to the working electrode to reduce the influence of Ohmic drop. Different electrochemical corrosion techniques-direct current (DC) and alternating current (AC) techniques-were applied. DC techniques; the open-circuit potential or corrosion potential $E_{\mathrm{corr}}$, the linear polarisation resistance (LPR), and the Taffel extrapolation method were carried out on each sample for the purpose of corrosion rate determination. DC measurements were performed on the potentiostat/galvanostat Princeton applied research, model 273A EG\&E. The corrosion parameters were recorded graphically and analytically using the software SoftCorr III (AMETEK Scientific Instruments, Princeton applied research, Berwyn, PA, USA). The measurements were performed in relation to the reference saturated calomel electrode (SCE) with known potential of $+0.242 \mathrm{~V}$ according to the standard hydrogen electrode.

Electrochemical impedance spectroscopy (EIS) from alternating current techniques was carried out in order to investigate the corrosion process at the interface between the sample surface and electrolyte solution. The impedance and the phase shift curves were plotted against the excitation frequency for each sample. The frequency applied in the research was in the range from $10,000 \mathrm{~Hz}$ to $1 \mathrm{~Hz}$ and an amplitude in the range of $1000 \mathrm{mV}$ root-mean-square (RMS). EIS was performed on the potentiostat AMETEK, Princeton applied research, model VersaSTAT3 with a typical three-electrode cell setup at room temperature in relation to the reference SCE. All measurements were performed in the solution of $3.5 \% \mathrm{NaCl}$.

\section{Results}

The characteristics of researched samples are presented in Table 2.

Table 2. Characteristics of researched samples [13,14].

\begin{tabular}{|c|c|c|c|c|c|c|c|c|}
\hline \multirow{2}{*}{ Mixture } & \multirow{2}{*}{ Sample } & \multicolumn{3}{|c|}{ Porosity } & \multirow{2}{*}{$\eta$-phase } & \multirow{2}{*}{$d_{\mathrm{WC}}, \mu \mathrm{m}$} & \multirow{2}{*}{$\begin{array}{c}\text { Measured } \\
\text { Density, } \mathrm{g} / \mathrm{cm}^{3}\end{array}$} & \multirow{2}{*}{$\rho, \%$} \\
\hline & & A & B & C & & & & \\
\hline \multirow{2}{*}{ WC9Co/1 } & WC-9Co/1V & A02 & B00, B02 & $\mathrm{C} 00$ & $\mathrm{~N}$ & $0.249 \pm 0.122$ & $14.45 \pm 0.06$ & 99.6 \\
\hline & WC-9Co/1S & A00 & B00 & $\mathrm{C} 00$ & $\mathrm{~N}$ & $0.192 \pm 0.073$ & $14.60 \pm 0.03$ & 100 \\
\hline \multirow[b]{2}{*}{ WC-9Co/2 } & WC-9Co/2V & $\mathrm{A} 02$ & B00, B02 & $\mathrm{C} 00$ & $\mathrm{~N}$ & $0.265 \pm 0.159$ & $14.51 \pm 0.05$ & 99.4 \\
\hline & WC-9Co/2S & A00 & B00 & $\mathrm{C} 00$ & $\mathrm{~N}$ & $0.243 \pm 0.086$ & $14.66 \pm 0.02$ & 100 \\
\hline \multirow{2}{*}{ WC-6Co/1 } & WC-6Co/1V & A04 & B02 & $\mathrm{C} 00$ & $\mathrm{~N}$ & $0.235 \pm 0.135$ & $14.70 \pm 0.08$ & 99.1 \\
\hline & WC-6Co/1S & $\mathrm{A} 02$ & B00 & $\mathrm{C} 00$ & $\mathrm{Y}$ & $0.216 \pm 0.078$ & $14.82 \pm 0.04$ & 99.9 \\
\hline \multirow{2}{*}{ WC6Co/4 } & WC-6Co/4V & A06 & B02 & $\mathrm{C} 00$ & $\mathrm{~N}$ & $0.175 \pm 0.155$ & $14.55 \pm 0.08$ & 98.6 \\
\hline & WC-6Co/4S & A04 & B00 & $\mathrm{C} 00$ & $\mathrm{Y}$ & $0.139 \pm 0.058$ & $14.74 \pm 0.04$ & 99.8 \\
\hline
\end{tabular}

As can be seen from Table 2, higher densities are achieved for higher Co content and bigger grain size of the starting powder. The achieved densities of all samples sintered in hydrogen are 
lower than the theoretical density. The degree of porosity of WC-9Co samples sintered in hydrogen is A02, predominantly B00, partially B02, without uncombined carbon or $\eta$-phase. The high degree of porosity with pore sizes larger than $2 \mu \mathrm{m}$ was obtained for the WC-6Co mixtures. The degree of porosity of the WC-6Co samples ranges from A04 to A06, B02 without uncombined carbon or $\eta$-phase. Additionally, small cracks occurred on samples sintered in hydrogen, especially WC-6Co/4V samples, resulting from one of the following technological operations: milling, waxing or granulation [13,14]. WC-9Co samples consolidated by sinter-HIP achieved theoretical densities while WC-6Co samples almost achieved theoretical density, in the range from $99.8 \%$ to $99.9 \%$. The degree of porosity of WC-9Co sinter-HIPed samples is A00, B00, without uncombined carbon or $\eta$-phase while the degree of porosity of WC-6Co sinter-HIPed samples ranges from A02 to A04, B00 without uncombined carbon. The $\eta$-phase was detected on the surface of samples WC-6Co/1S and WC-6Co/4S consolidated by the sinter-HIP process. Samples with $\eta$-phase were selected in order to investigate the influence of $\eta$-phase on the electrochemical properties of WC-Co cemented carbides. Some investigations indicate that $\eta$-phase could improve the corrosion resistance of cemented carbides [10-12]. Samples WC-9Co/1S, WC-6Co/4V and WC-6Co/4S with a WC grain size $d_{\mathrm{WC}}<200 \mathrm{~nm}$ can be classified as nanostructured WC-Co cemented carbides while all other samples with a WC grain size $d_{\text {WC }}>200$, near $200 \mathrm{~nm}$, can be classified as near-nano cemented carbides. The results of electrochemical DC techniques; corrosion potential $E_{\text {corr, }}$ and potentiodynamic polarization curves (Taffel) are presented in Table 3 and in Figures 1 and 2.

Table 3. The results of electrochemical DC techniques [15].

\begin{tabular}{lccccccc}
\hline Sample & $\boldsymbol{T}_{\mathbf{s}}\left({ }^{\circ} \mathbf{C}\right)$ & $\begin{array}{c}\boldsymbol{E}_{\text {corr }} \mathbf{v s .} \\
\mathbf{S C E}(\mathbf{m V})\end{array}$ & $\begin{array}{c}\boldsymbol{R}_{\mathbf{p}} \\
\left(\mathbf{k} \boldsymbol{\Omega} \cdot \mathbf{c m}^{\mathbf{2}}\right)\end{array}$ & $\begin{array}{c}\boldsymbol{b}_{\mathbf{a}} \\
(\mathbf{V} / \mathbf{d e c})\end{array}$ & $\begin{array}{c}\boldsymbol{b}_{\mathbf{c}} \\
(\mathbf{V} / \mathbf{d e c})\end{array}$ & $\begin{array}{c}j_{\text {corr }} \\
\left(\boldsymbol{\mu} \mathbf{A} / \mathbf{c m}^{2}\right)\end{array}$ & $\begin{array}{c}\boldsymbol{v}_{\text {corr }} \\
(\mathbf{m m} / \mathbf{a})\end{array}$ \\
\hline WC-9Co/1V & $20 \pm 2$ & -241 & 4.66 & 0.0579 & 0.3992 & 3.755 & 0.0678 \\
WC-9Co/1S & $20 \pm 2$ & -418 & 2.35 & 0.1707 & 1.0180 & 19.310 & 0.3488 \\
WC-9Co/2V & $20 \pm 2$ & -334 & 10.26 & 0.1593 & 0.2742 & 2.269 & 0.0409 \\
WC-9Co/2S & $20 \pm 2$ & -438 & 4.94 & 0.0649 & 0.8492 & 7.879 & 0.1419 \\
WC-6Co/1V & $20 \pm 2$ & -128 & 101.10 & 0.2260 & 0.2014 & 0.352 & 0.0064 \\
WC-6Co/1S & $20 \pm 2$ & -112 & 71.96 & 0.0275 & 0.1373 & 0.292 & 0.0052 \\
WC-6Co/4V & $20 \pm 2$ & -347 & 17.55 & 0.0041 & 0.2740 & 1.660 & 0.0030 \\
WC-6Co/4S & $20 \pm 2$ & -214 & 39.72 & 0.2078 & 0.2718 & 1.065 & 0.0193 \\
\hline
\end{tabular}

$T_{\mathrm{s}}$-measured temperature; $E_{\mathrm{corr}}$-corrosion potential; $R_{\mathrm{p}}$-polarisation resistance; $b_{\mathrm{a}}$-slope of anodic Tafell curve; $b_{\mathrm{c}}$-slope of cathodic Tafell curve; $j_{\text {corr }}$-corrosion current density; $v_{\text {corr }}$-corrosion rate.

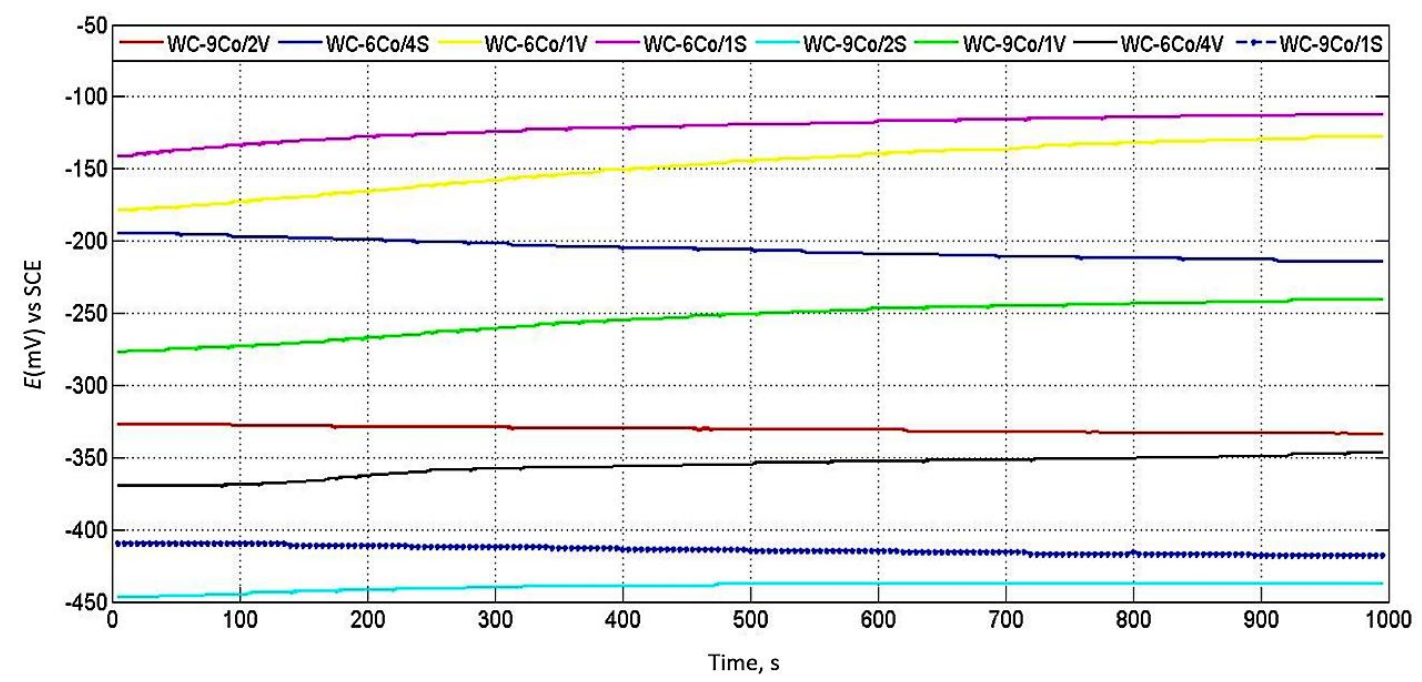

Figure 1. Corrosion potential $E_{\text {corr }}$ of samples [15]. 


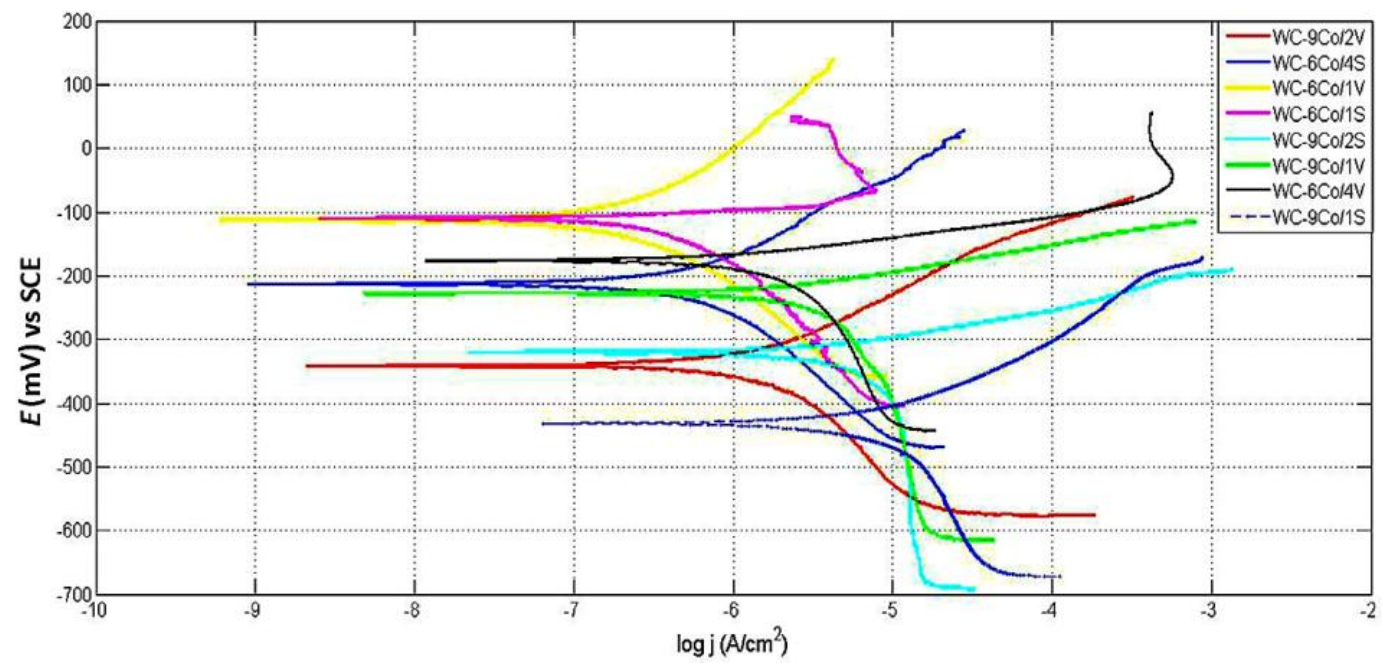

Figure 2. Potentiodynamic polarisation curves (Tafel extrapolation diagram) of samples [15].

The results of electrochemical impedance spectroscopy (EIS) are presented in Table 4. After comparing the measured and calculated values of the impedance in the Nyquist diagrams, the model of equivalent electrical circuit (EEC) that best describes the reactions and changes on the samples' surface in the electrolyte was selected using data analysis software ZSimpWin Version 3.2. Model type $\mathrm{R}(\mathrm{QR}(\mathrm{QR})(\mathrm{QR})(\mathrm{CR}))$ was selected for all samples. The schematic diagram of the selected EEC circuit with components is presented in Figure 3.

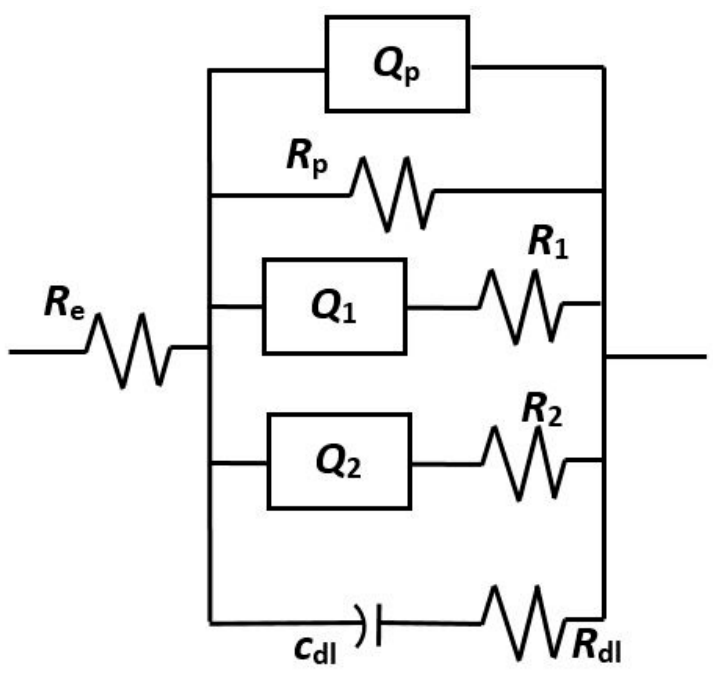

Figure 3. Selected model of EIS equivalent electrical circuit.

Model type $\mathrm{R}(\mathrm{QR}(\mathrm{QR})(\mathrm{QR})(\mathrm{CR}))$ assumes the formation of two non-conductive porous oxide layers on the surface of samples as a result of the reaction between the electrolyte and the working electrode. 
Table 4. The results of EIS.

\begin{tabular}{|c|c|c|c|c|c|c|c|c|c|c|c|c|}
\hline Sample & $R_{\mathrm{e}}, \Omega \cdot \mathrm{cm}^{2}$ & $Q_{\mathrm{p}}-Y_{\mathrm{o}}, \mathrm{S} \cdot \mathrm{s}^{\mathrm{n}} \cdot \mathrm{cm}^{2}$ & $n_{p}$ & $R_{\mathrm{p}}, \Omega \cdot \mathrm{cm}^{2}$ & $Q_{1}-Y_{01}, \mathrm{~S} \cdot \mathrm{s}^{\mathrm{n}} \cdot \mathrm{cm}^{2}$ & $n_{1}$ & $R_{1}, \Omega \cdot \mathrm{cm}^{2}$ & $Q_{2}-Y_{02}, \mathrm{~S} \cdot \mathrm{s}^{\mathrm{n}} \cdot \mathrm{cm}^{2}$ & $n_{2}$ & $R_{2}, \Omega \cdot \mathrm{cm}^{2}$ & $C_{\mathrm{dl}}, \mathrm{F} / \mathrm{cm}^{2}$ & $R_{\mathrm{dl}}, \Omega \cdot \mathrm{cm}^{2}$ \\
\hline WC-9Co/1V & 0.002 & $1.6 \times 10^{-7}$ & 0.99 & $1.2 \times 10^{4}$ & $2 \times 10^{-5}$ & 0.79 & 63.4 & $1.6 \times 10^{-4}$ & 0.91 & 12.8 & $1.3 \times 10^{-5}$ & 35.44 \\
\hline WC-9Co/1S & 11.19 & $2.1 \times 10^{-4}$ & 0.10 & $1.5 \times 10^{6}$ & $1.6 \times 10^{-4}$ & 0.70 & $1.0 \times 10^{2}$ & $1.3 \times 10^{-5}$ & 0.90 & 80.5 & $4.2 \times 10^{-5}$ & 0.15 \\
\hline WC-9Co/2V & 0.03 & $8.8 \times 10^{-6}$ & 0.56 & $9.5 \times 10^{6}$ & $3 \times 10^{-5}$ & 0.78 & $7.9 \times 10^{2}$ & $6.5 \times 10^{-6}$ & 1.00 & 341.3 & $5.5 \times 10^{-5}$ & 3.97 \\
\hline WC-9Co/2S & 0.003 & $8.9 \times 10^{-5}$ & 0.86 & $2.1 \times 10^{6}$ & $4 \times 10^{-4}$ & 1.00 & 47.6 & $7.5 \times 10^{-4}$ & 0.71 & 7.1 & $1.9 \times 10^{-4}$ & 74.40 \\
\hline WC-6Co/1V & 0.60 & $5.0 \times 10^{-5}$ & 0.16 & $1.5 \times 10^{8}$ & $4 \times 10^{-5}$ & 0.26 & $3.6 \times 10^{3}$ & $4.2 \times 10^{-5}$ & 0.79 & 193.5 & $3.0 \times 10^{-5}$ & 2.56 \\
\hline WC-6Co/1S & 0.024 & $3.2 \times 10^{-6}$ & 0.04 & $6.4 \times 10^{6}$ & $1 \times 10^{-5}$ & 0.82 & $3.6 \times 10^{3}$ & $3 \times 10^{-6}$ & 1.00 & 628.6 & $2.3 \times 10^{-5}$ & 2.56 \\
\hline WC-6Co/4V & 16.10 & $1.3 \times 10^{-8}$ & 0.98 & $1.0 \times 10^{4}$ & $1.5 \times 10^{-4}$ & 0.88 & $2.4 \times 10^{3}$ & $2.6 \times 10^{-5}$ & 0.92 & 16.4 & $1.6 \times 10^{-5}$ & 10.30 \\
\hline WC-6Co/4S & 0.03 & $1.2 \times 10^{-4}$ & 1.00 & $8.1 \times 10^{6}$ & $3.4 \times 10^{-2}$ & 0.51 & $7.5 \times 10^{2}$ & $1.8 \times 10^{-6}$ & 0.97 & 204.8 & $1.1 \times 10^{-4}$ & 1.13 \\
\hline
\end{tabular}

$R_{\mathrm{e}}$ - electrolyte solution resistance between the working electrode and the reference electrode in a three-electrode cell; $R_{\mathrm{p}}$ - polarization resistance or resistance to charge transfer on the electrode/electrolyte interface; $Q_{\mathrm{p}}$ or Constant Phase Element (CPE)-modified phase element introduced to improve the representation of the impedance by model and depends on the empirical constant for determination of $Q_{n}$ behavior which represents the capacitive properties of the layers and is in the range 0 to 1 . If $n=0$, $Q_{P}$ will act as a resistor, and if $n=1$, $Q_{\mathrm{P}}$ will act as a capacitor; $R_{1}, R_{2}$ 一the resistance of the oxide layers; $Q_{1}, Q_{2}$-modified phase elements for the impedance of layers. Determination of $Q_{1}$ and $Q_{2}$ is provided through empirical constants $n_{1}$ and $n_{2} ; C_{\mathrm{dl}}$-double layer capacity at the interface; $R_{\mathrm{dl}}$-resistance bilayer electrode/electrolyte interfacial boundaries. 


\section{Analysis and Discussion}

\subsection{Potentiodynamic Polarisation Behaviour, DC Techniques}

The corrosion potentials $E_{\text {corr }}$ of consolidated samples varied in a narrow range as presented in Figure 1. Samples WC-6Co/1V, WC-6Co/1S, WC-9Co/2S, WC-9Co/1V and WC-6Co/4V recorded a change of $E_{\text {corr }}$ from more negative to less negative values, indicating that the surfaces of the samples are getting passivated. Samples WC-9Co/2V, WC-6Co/4S and WC-9Co/1S recorded a change from less negative towards more negative values, indicating surface activity, i.e., corrosion of samples in the electrolyte. Still, these changes are not significant and the corrosion potential of each sample varied in a very narrow range. The relationship between the electrochemical parameters; polarization resistance $R_{\mathrm{p}}$ and corrosion current density $j_{\text {corr }}$ with respect to the consolidation process, grain growth inhibitors and WC powder size, is presented graphically in Figures 4 and 5.

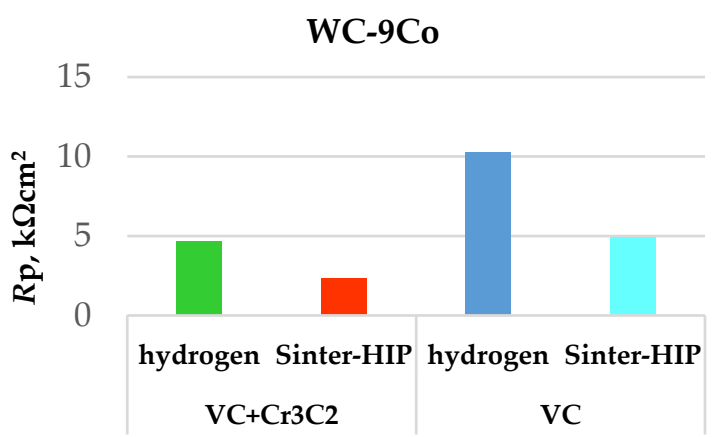

(a)

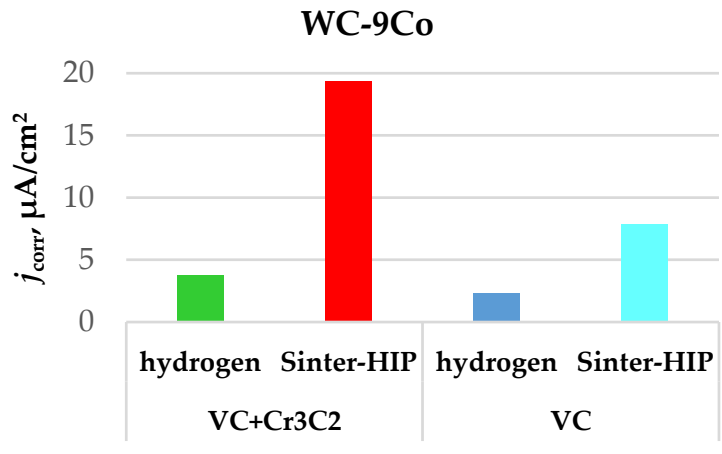

(b)

Figure 4. Correlation of electrochemical parameters and GGIs for WC-9Co. (a) Correlation of polarisation resistance and GGIs; (b) Correlation of corrosion current density and GGIs.

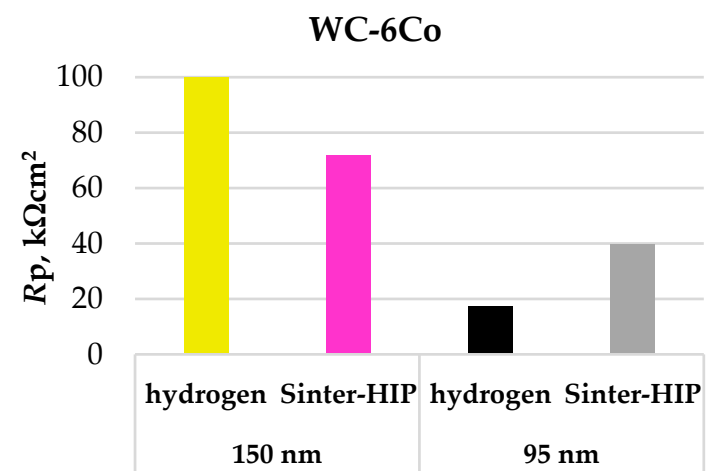

(a)

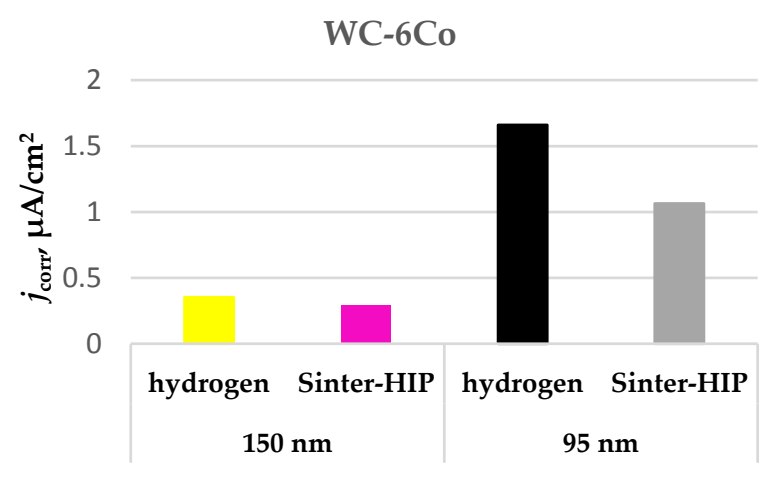

(b)

Figure 5. Correlation of electrochemical parameters and WC powder size for WC-6Co. (a) Correlation of polarisation resistance and WC powder size; (b) Correlation of corrosion current density and WC powder size.

Due to the higher value of $R_{\mathrm{p}}$ and lower values of $j_{\text {corr }}$ it can be concluded that samples with an addition of only $0.27 \% \mathrm{VC}$ have higher corrosion resistance compared to samples with an addition of $0.26 \% \mathrm{VC}$ and $0.45 \% \mathrm{Cr}_{3} \mathrm{C}_{2}$ for both of the processes. From the published literature, it can be found that the refractory metal carbides such as $\mathrm{VC}, \mathrm{Cr}_{3} \mathrm{C}_{2}$, titanium carbide TiC, tantalum carbide $\mathrm{TaC}$, even ruthenium $\mathrm{Ru}$ and rhenium Re increase corrosion resistance [16-22]. The latest research from Machio has found that smaller additions- $0.4 \%$ of VC to WC-Co cemented carbides-increase corrosion current density and predispose samples to pitting corrosion in $\mathrm{NaCl}$ and synthetic mine 
water (SMW). The mentioned effect was explained by the fact that VC reduces the amount of $\mathrm{W}$ atoms dissolving in the binder during sintering forming $(\mathrm{V}, \mathrm{W}) \mathrm{C}$ film around the WC grains [23]. On the other hand, $\mathrm{Cr}_{3} \mathrm{C}_{2}$ forms a very protective $\mathrm{Cr}_{2} \mathrm{O}_{3}$ film (chromium-rich film) on the surface of the binder, increasing the corrosion resistance [18]. From research conducted, it can be concluded that an addition of $0.26 \% \mathrm{VC}$ together with $0.45 \% \mathrm{Cr}_{3} \mathrm{C}_{2}$ to the starting WC powder reduces the positive influence of $\mathrm{Cr}_{3} \mathrm{C}_{2}$ interfering with the $\mathrm{Cr}_{2} \mathrm{O}_{3}$ film.

It can be seen from the Figure 4 that better corrosion resistance was recorded for the samples sintered in hydrogen atmosphere. Although, theoretically, the corrosion resistance of samples with a higher degree of porosity should be lower compared to full density samples, from the conducted research, it was found that the samples with lower densities possess better corrosion resistance. The density achieved for WC-9Co samples is in the range from $99.4 \%$ to $99.6 \%$ of the theoretical density, which is a highly relevant result for the process of sintering in hydrogen atmosphere.

Due to a higher value of $R_{\mathrm{p}}$ and lower values of $j_{\text {corr, }}$ it can be concluded that the samples consolidated by $150 \mathrm{~nm}$ WC showed better corrosion resistance compared to samples consolidated by $95 \mathrm{~nm}$ WC powder. This behaviour was noted for both of the consolidation processes used. The samples consolidated by $95 \mathrm{~nm}$ starting WC powder, containing a higher addition of GGIs, showed lower values of $R_{\mathrm{p}}$ and higher values of $j_{\text {corr }}$, indicating lower corrosion resistance. The combination of VC and $\mathrm{Cr}_{3} \mathrm{C}_{2}$ leads to lower corrosion resistance.

The polarization resistance value $R_{\mathrm{p}}$ of the sample WC-6Co/4S, consolidated by sinter-HIP process and containing $\eta$-phase, amounts to $39.72 \mathrm{k} \Omega \cdot \mathrm{cm}^{2}$ while the corrosion current density amounts to $1.065 \mu \mathrm{A} / \mathrm{cm}^{2}$. On the other hand, the polarization resistance value of the sample $\mathrm{WC}-6 \mathrm{Co} / 4 \mathrm{~V}$ amounts to $17.55 \mathrm{k} \Omega \cdot \mathrm{cm}^{2}$, which is two times lower compared to WC-6Co/4S sample. The corrosion current density of sample WC-6Co/4V is higher and amounts to $1.660 \mu \mathrm{A} / \mathrm{cm}^{2}$. This behaviour can be related to two different statements. The first one is connected with the microstructural characteristics of the sample WC-6Co/4V such as lower density, higher degree of porosity and cracks occurring on the sample surface which enhance the corrosion rate. Another one might be related to $\eta$-phase occurring on the sample WC-6Co/4S, indicating that $\eta$-phase changes the electrochemical behavior of the cemented carbides. It is assumed that $\eta$-phase enhances the formation of a passive layer on the samples' surfaces, thereby reducing the tendency of the sample dissolution and increasing the stability of oxides forming therewith a passive layer on the sample surface.

Comparing samples WC-6Co/1V and WC-6Co/1S, the situation gets more complicated, since the polarization resistance of sample $\mathrm{WC}-6 \mathrm{Co} / 1 \mathrm{~S}$ with $\eta$-phase is lower and amounts to $71.96 \mathrm{k} \Omega \cdot \mathrm{cm}^{2}$ but the value of corrosion current density is also lower and amounts to $0.292 \mu \mathrm{A} / \mathrm{cm}^{2}$, indicating better corrosion resistance. Potentiodynamic polarization measurement (Tafell method) is used in the first place to determine the corrosion current density and the type of the dominant chemical process-reduction or oxidation-occurring on the sample's surface. For that reason, EIS measurements were performed in order to determine more precisely the resistance of samples in the examined electrolyte.

It can be seen from the potentiodynamic curves (Figure 2) that the samples with 6 wt \% Co showed better corrosion resistance compared to the samples with $9 \mathrm{wt} \%$ Co which is in line with the fact that Co binder is the most susceptible to corrosion in acid and neutral media [13]. WC-6Co/1S has the lowest corrosion current density of $0.292 \mu \mathrm{A} / \mathrm{cm}^{2}$ while the highest corrosion current density of $19.31 \mu \mathrm{A} / \mathrm{cm}^{2}$ was measured for the sample WC-9Co/1S with the most homogeneous microstructure and the smallest grain size. Such a behaviour can be related to the influence of galvanic corrosion between WC and Co.

Comparing samples consolidated by the same mixtures but by different processes, it can be seen that the samples sintered in hydrogen-excluding the sample with $\eta$-phase and a high degree of porosity-showed better corrosion resistance. 


\subsection{EIS Analysis}

EIS measurements were performed in order to determine more precisely the polarisation resistance of samples in the examined electrolyte. The Nyquist diagram of sample WC-6Co/4S with the corresponding EEC model applied for the simulation of EIS results is presented in Figure 6. The same model type $\mathrm{R}(\mathrm{QR}(\mathrm{QR})(\mathrm{QR})(\mathrm{CR}))$ was selected for all samples.

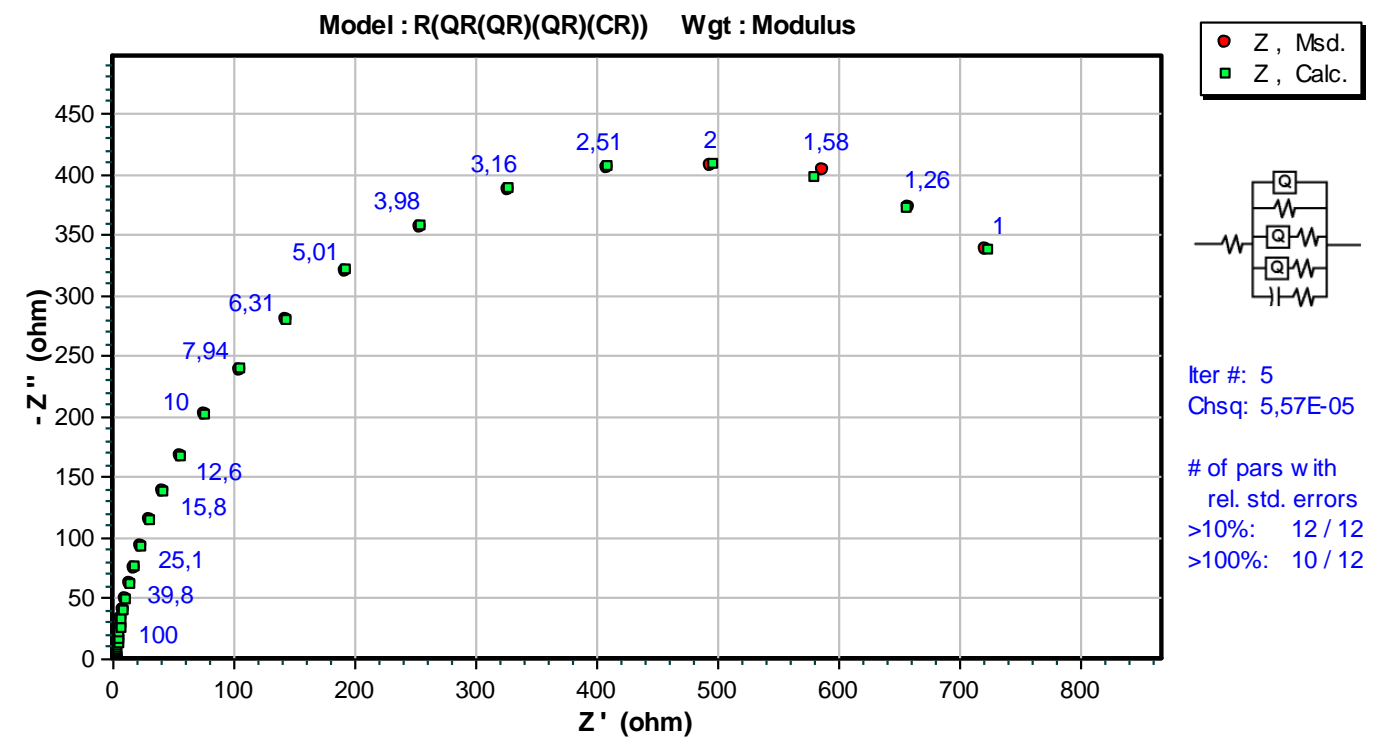

Figure 6. Nyquist plot of WC-6Co/4S.

Graphical presentation of polarization resistance $R_{\mathrm{p}}$ with respect to the consolidation process, grain growth inhibitors and WC powder size is presented graphically in Figure 7.

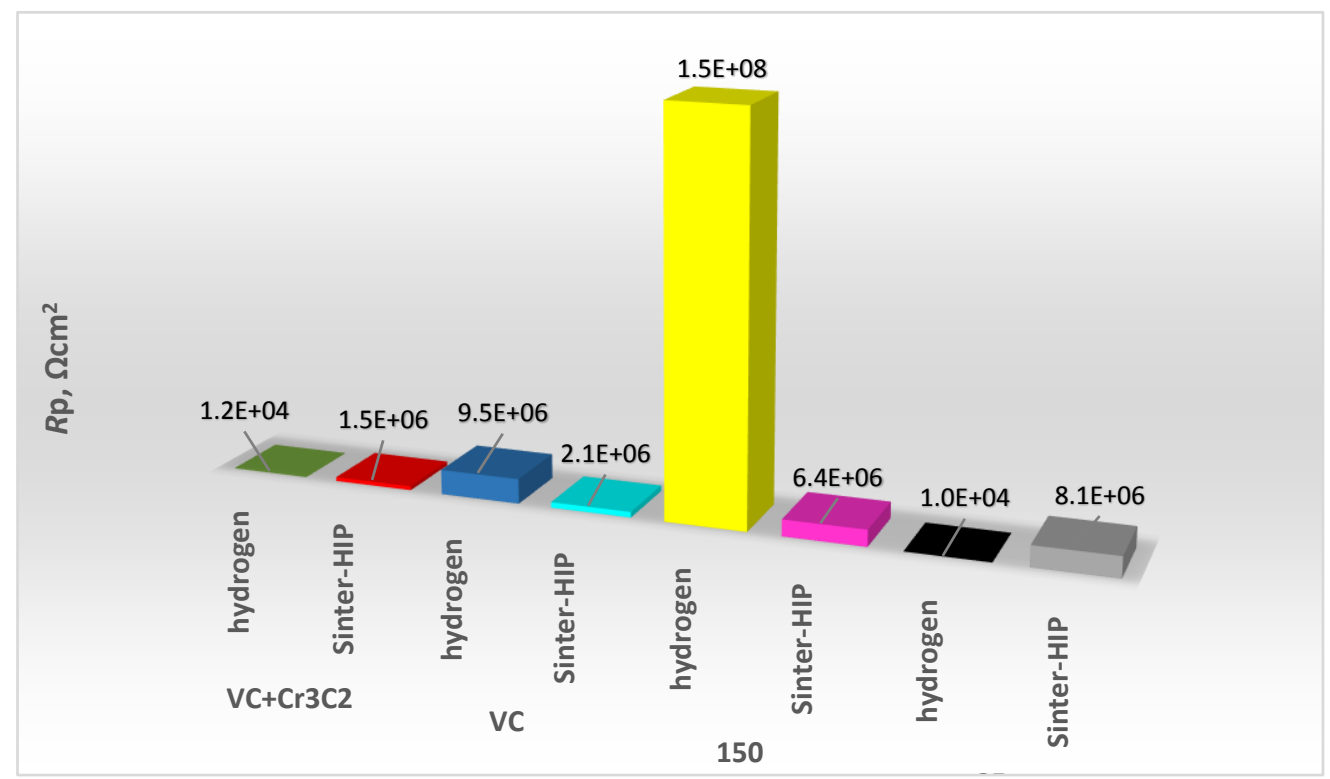

Figure 7. Graphical presentation of polarisation resistance.

As can be seen from Figure 7 and Table 4, the highest value of polarization resistance was measured for sample WC-6Co/1V and amounts to $1.5 \times 10^{8} \Omega \cdot \mathrm{cm}^{2}$, followed by samples WC-9Co/2V with the polarization resistance of $9.5 \times 10^{6}$; WC-6Co/4S with the polarization resistance of $8.1 \times 10^{6} \Omega \cdot \mathrm{cm}^{2}$; 
and WC-6Co/1S with the polarization resistance of $6.4 \times 10^{6} \Omega \cdot \mathrm{cm}^{2}$. The samples WC-9Co/2V, WC-6Co $/ 4 \mathrm{~S}$, WC-6Co/1V and WC-6Co/1S have up to several times higher values of $R_{\mathrm{p}}$ compared to other samples, indicating better corrosion resistance. The results are in line with the results obtained by DC linear polarization techniques.

The lowest polarization resistance value was measured for sample WC-6Co/4Vwith a high degree of porosity, lower density and cracks on the sample surface. The exception is the sample WC-9Co/1V that showed a very low value of polarization resistance that is not in line with potentiodynamic polarisation measurements.

In order to understand the behavior of samples with $\eta$-phase and to prove the statement about the formation of oxide layers on the sample's surface, the graphical presentation of the oxide layers' resistance $R_{2}$ of WC-6Co samples is presented in Figure 8.

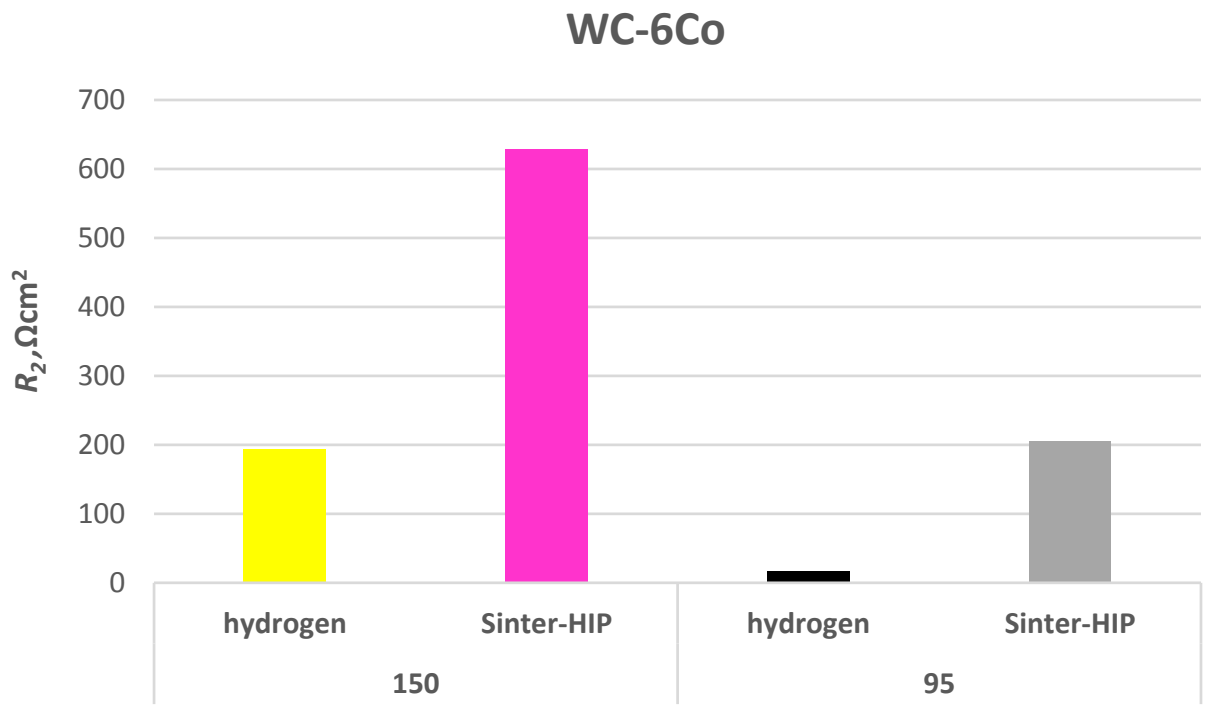

Figure 8. Graphical presentation of the oxide layer resistance.

As can be seen from Figure 8, the samples with $\eta$-phase WC-6Co/1S and WC-6Co/4S possess higher resistance to the oxide layer $R_{2}$ compared to WC-6Co/1V and WC-6Co $/ 4 \mathrm{~V}$. As can be seen from the Table 4, the samples WC-9Co/2S, WC-9Co/1V, WC-6Co/4V and WC-9Co/1S have lower resistance of the oxide layers, indicating that the electrolyte penetrates the pores between each layer, contributing to the faster dissolution of the sample surface. Accordingly, it can be confirmed that $\eta$-phase changes the electrochemical behavior of cemented carbides by enhancing the formation of a passive oxide layer on the sample's surface, thereby reducing the tendency of the sample dissolution and increasing the stability of oxides forming therewith a passive layer on the sample surface. In order to define an influence of $\eta$-phase on the electrochemical corrosion behaviour of nanostructured cemented carbides, more detailed research which includes XRD analysis and magnetic saturation is planned in the future research.

\section{Conclusions}

The following conclusions can be drawn from the conducted research:

(i). The consolidation process contributed to electrochemical corrosion resistance; better corrosion resistance was observed for samples consolidated by sintering in hydrogen, even though the densities of samples are lower compared to sinter-HIPed samples, excluding the sample with a high degree of porosity and cracks on the surface.

(ii). Grain growth inhibitors in the starting powders influenced the electrochemical corrosion resistance; samples with only $0.27 \%$ VC showed better corrosion resistance compared to samples 
with an addition of $0.26 \% \mathrm{VC}$ and $0.45 \% \mathrm{Cr}_{3} \mathrm{C}_{2}$. The combination of $\mathrm{VC}$ and $\mathrm{Cr}_{3} \mathrm{C}_{2}$ leads to lower corrosion resistance.

(iii). The size of the starting powder and amount of GGIs influenced the electrochemical corrosion resistance; samples consolidated by $150 \mathrm{~nm} \mathrm{WC}$ showed better corrosion resistance compared to samples consolidated by $95 \mathrm{~nm}$ WC powder.

(iv). $\eta$-phase changes the electrochemical behaviour; enhances the formation of a passive layer on the samples' surfaces, thereby reducing the tendency of the sample dissolution and increasing the stability of oxides forming therewith a passive layer on the sample surface. In order to define an influence of $\eta$-phase on the electrochemical corrosion behaviour of nanostructured cemented carbides, more detailed research which includes $\mathrm{XRD}$ analysis and magnetic saturation is planned in the future research.

(v). The samples with lower Co content showed better corrosion resistance, confirming a selective leaching of the Co in neutral media.

Author Contributions: Željko Alar and Vesna Alar performed electrochemical measurements and analyzed the data, Aleksandrov Fabijanić performed characterization of cemented carbides and wrote the paper.

Conflicts of Interest: The authors declare no conflict of interest.

\section{References}

1. Hochstrasser-Kurz, S. Mechanistic Study of the Corrosion Reactions on WC-Co Hardmetal in Aqueous Solution-An Investigation by Electrochemical Methods and Elemental Solution Analysis; Shaker Verlag: Aachen, Germany, 2006.

2. Hochstrasser-Kurz, S.; Mueller, Y.; Latkoczy, C.; Virtanen, S.; Schmutz, P. Analytical characterisation of the corrosion mechanism and inductively coupled plasma mass spectroscopy. Corr. Sci. 2007, 49, 2002-2020. [CrossRef]

3. Sandvik: Cemented Carbide, Sandvik New Developments and Applications. Available online: http://www2. sandvik.com/sandvik/0130/HI/SE03411.nsf/7a5364adb7735b05412568c70034ea1b/651f6e334db04c46c1257 07600562c88/\$FILE/Cemented+Carbide.pdf (accessed on 25 April 2015).

4. Human, A.M.; Exner, H.E. Electrochemical behavior of tungsten-carbide hardmetals. Mater. Sci. Eng. 1996, A209, 180-191. [CrossRef]

5. Human, A.M. The Corrosion of Tungsten Carbide-Based Cemented Carbides. Ph.D. Thesis, Technische Hochschule Darmstadt, Darmstadt, Germany, 1994.

6. Tarrago, J.M.; Fargas, G.; Jimenez-Pique, E.; Felip, A.; Isern, L.; Coureaux, D.; Roal, J.J.; Al-Dawery, I.; Fair, J.; Llanes, L. Corrosion damage in WC-Co cemented carbides: Residual strength assessment and 3D FIB-FESEM tomography characterization. Powder Metall. 2014, 57, 5. [CrossRef]

7. Sacks, N. The Wear and Corrosive-Wear Response of Tungsten Carbide-Cobalt Hardmetals under Woodcutting and Three Body Abrasion Conditions; Faculty of Engineering of the University of Erlangen-Nürnberg: Doktor-Ingenieur, Germany, 2002.

8. Zhang, L.; Wan, Q.; Huang, B.; Liu, Z.; Zhu, J. Effects of WC Grain Sizes and Aggressive Media on the Electrochemical Corrosion Behaviours of WC-Co Cemented Carbides. In Proceedings of the EURO PM2015-HM-Modelling and Characterisation, Reims, France, 4-7 September, 2015.

9. Tarrago, J.M.; Fargas, G.; Jimenez-Pique, E.; Dorvlo, S.; Llanes, L. Influence of Carbide Grain Size on the Corrosion damage in WC-Co cemented carbides: Electrochemical Measurement, residual strength and 3D FIB/FESEM characterisation of Induced Damage. In Proceedings of the World PM2016, Hamburg, Germany, 9-13 October 2016; pp. 509-514.

10. Sutthiruangwong, S.; Mori, G. Influence of refractory metal carbide addition on corrosion properties of cemented carbides. Mater. Manuf. Proc. 2005, 20, 47-56. [CrossRef]

11. Sutthiruangwong, S.; Mori, G. Corrosion properties of Co-based cemented carbides in acidic solutions. Int. J. Refract. Metals Hard Mater. 2003, 21, 135-145. [CrossRef]

12. Mori, G.; Zitter, H.; Lackner, A.; Schretter, M. Influencing the Corrosion Resistance of Cemented Carbides by addition of $\mathrm{Cr}_{2} \mathrm{C}_{3}, \mathrm{TiC}$ and $\mathrm{TaC}$. In Proceedings of the 15th International Plansee Seminar, Plansee Holding AG, Reutte, Austria, May 2001; Volume 2. 
13. Aleksandrov Fabijanić, T.; Alar, Ž.; Ćorić, D. Influence of Consolidation Process and Sintering Temperature on Microstructure and Mechanical properties of Near Nano- and Nanostructured WC-Co Cemented Carbides. Int. J. Refract. Metals Hard Mater. 2016, 54, 82-89. [CrossRef]

14. Fabijanić, T.A.; Jakovljević, S.; Franz, M.; Jeren, I. Influence of Grain Growth Inhibitors and Powder Size on the Properties of Ultrafine and Nanostructured Cemented Carbides Sintered in Hydrogen. Metals 2016, 6, 198. [CrossRef]

15. Majdak I. Corrosion resistance of nanostructured hardmetals, Faculty of Mechanical Engineering and Naval Architecture, Zagreb, Croatia. Unpublished work, 2016.

16. Potgieter, J.H.; Olubambi, P.; Potgieter-Vermaak, S.S. The Corrosion Behaviour of WC-Co-Ru Alloys in Aggressive Chloride Media. Int. J. Electr. 2014, 2014, 594871. [CrossRef]

17. Wentzel, E.J.; Allen, C. The erosion-corrosion resistance of tungsten-carbide hard metals. Int. J. Refract. Metals Hard Mater. 1997, 15, 81-87. [CrossRef]

18. Tomlinson, W.J.; Ayerst, N.J. Anodic polarization and corrosion of WC-Co hardmetals containing small amounts of $\mathrm{Cr}_{3} \mathrm{C}_{2}$ and/or VC. J. Mater. Sci. 1989, 24, 2348-2352. [CrossRef]

19. Bonjour, C. Effects of ruthenium additions on the properties and machining behaviour of WC-Co hard metals. In Proceedings of the EURO PM2014-Powder Metallurgy Tool Material, Vienna, Austria, 17-21 October 2004.

20. Lisovsky, A.F.; Tkachenko, N.V.; Kebko, V. Structure of a binding phase in re-alloyed WC-Co cemented carbides. Int. J. Refract. Metals Hard Mater. 1991, 10, 33-36. [CrossRef]

21. Ringas, C.; Robinson, F.P.A.; Luyckx, S.B.; Sellschop, J.P.F. Corrosion behaviour of ion implanted WC-Co and WCNi alloys in acid and chloride containing media. Surf. Eng. 1990, 6, 194-198. [CrossRef]

22. Sutthiruangwong, S.; Mori, G.; Kosters, R. Passivity and pseudopassivity of cemented carbides. Int. J. Refract. Metals Hard Mater. 2005, 23, 129-136. [CrossRef]

23. Machio, C.N.; Konadu, D.S.; Potgieter, J.H.; Potgieter-Vermaak, S.; van der Merwe, J. Corrosion of WC-VC-Co Hardmetal in Neutral Chloride Containing Media. ISRN Corr. 2013, 2013, 506759. [CrossRef]

(c) 2017 by the authors. Licensee MDPI, Basel, Switzerland. This article is an open access article distributed under the terms and conditions of the Creative Commons Attribution (CC BY) license (http:/ / creativecommons.org/licenses/by/4.0/). 